MARKETING AND BRANDING
RESEARCH $\begin{gathered}\text { INDUSTRIAL } \\ \text { MANAGEMENT } \\ \text { INSTITUTE }\end{gathered}$

\title{
The Impact of Packaging on the Competitiveness of Export Products
}

\author{
Mohammad ali Rasoulzadeh \\ ${ }^{1}$ Department of Management, Ardabil Branch, Islamic Azad University, Ardabil, Iran
}

\begin{abstract}
Keywords:

Packaging,

Competitiveness,

Products, Export

Correspondence:

m.rasoulzadeh2018@gm ail.com

The purpose of this study is to investigate the effect of packaging on the competitiveness of the export products in Ardabil province. The population of the study is the factories of the industrial town of Ardabil in which 20 factories were selected randomly. The data collecting tool in this research is a 20 -item questionnaire that its questions are tailored to the response and are fitted with a five-point Likert scale. To analyze the obtained information, firstly, the frequency table of each question was formed using the percentage method. The percentage of frequency is calculated and the result of each question are listed below each question. After analyzing each question, we analyze the research hypotheses, which is accompanied by a graphic representation of its results. Input analysis has also been used for inferential analysis. The results showed that there is a meaningful relationship between the amount of good packaging on purchasing decision of customers. There is a meaningful relationship between size and shape of appropriate packaging and sales volume. There is also a meaningful relationship between the factors such as color and design in packaging and sales of products.
\end{abstract}

(C)AIMI Journals

\section{Introduction}

As the country's increasing demand for non-oil exports develops, the proper packaging of products, especially in the food industry, becomes more and more important every day. However, the private sector has no problem in investing in this sector, but it requires the use of subsidized facilities from the government. In the first stage of the implementation of the above-mentioned plan, the storage and packaging of fruits and vegetables will be carried out by the end of this year, which, of course, requires short, medium and long-term programs. At the same time, packaging in accordance with international standards should not be forgotten, 
which itself needs to invest in this field and use the technology of the day. Many marketers consider packing with other marketing mixes, namely, price, commodity, location and advertising promotion as the fifth (Kotler \& Armstrong, 2010).

Appropriate packaging will prepare the necessary incentives for production to the producers and, to some extent, preserve them against the imitator competitors, and ultimately provide a greater variety and choice for the customer. Packaging is a kind of employment opportunity and an important helper for the effectiveness of customer relationship management (CRM) and the effectiveness of exports in order to transfer the message to the purchaser. Designing a suitable packaging is considered as a convenience for the consumer and leads to the value of advertising and profit for the manufacturer. Various factors contribute to the increasing use of packaging as a marketing tool, including self-service in large stores, consumer's comfort (access and reliability), creating a mental image of the company and brand and an opportunity for innovation (Faraji, 2011).

For an export product manufacturer, the first step is to determine the concept of packaging that determines what packaging is, in principle, what to do for a specific item, whether the primary purpose of packing is to preserve the product or to introduce a new and innovative distribution method of content or is it responsible for transmitting a message about a product or company or has another purpose? After determining the packaging concept, other packaging components such as size, shape, raw materials and color must be considered and matched, and, finally, pre-sales tests must be done. In order to grow the country's exports, we need an appropriate packaging to attract and increase the number of customers. We can significantly increase the country's exports rate by the proper design and packaging of goods and products. The impact of packaging on export development is currently in the country's date production is more than 1 million tons, which has increased the export of this product by using packaging and designing. The design and packaging of Iranian goods should be based on the tradition and culture of the country in order to provide the basis for cultural growth. Japan, with its design and packaging based on its traditions, has been able to promote its cultural position along with economic growth. According to Iran's packaging authorities, Iran is ranked as the top first out of 10 eco-countries in the design, printing and packaging industries (Faraji, 2011).

In the past 28 years, a plan for the construction and commissioning of a packaging research center was launched in Iran. The project, which was aimed at developing a packaging industry, followed by foreign exchange earnings, could have made Iran the largest center for packaging research in the Middle East. However, nowadays one of the main problems of food industry producers is the lack of proper packaging to export the mentioned products abroad. The final stage in any product, both artistic and industrial, is the topic of the presentation. This is the point where the introduction of the product takes place for the purpose of purchase and sense of independence (Garcia, 2003).

Perhaps this stage is one of the missing issues, especially in our country's handicrafts. In the expression of the difference between modern and classical art, it has been said that classical art has shown nature figures in its best form, but New Art says that nature must pass from the filter of the artist's mind to turn in to art (Rezainezhad, 2011). 
We believe that the packaging is an artistic-industrial field, that is to say, to take advantage of its goals, the attention should be paid to both the categories of art and technology (Ortega, 2015).

If we consider packing in view of art, we have to say that each packaging product has three main objectives: Attention - Creating an unforgettable visual state - Sending a message. The best way to achieve the two primary goals is to take into account visual effects and the use of visual literacy. The design of the package will determine if anyone will stop enough for what you provide as a commodity and communicative message. Meanwhile, using the right ingredients and matching them with the packaged product can be very effective in attracting customer's trust and attention.

Packing is, in fact, the language, identity, and character of the product. The more intelligible packing, the better introduction of the product. The role of good packaging is to attract customers' attention and influence the five senses and their emotions. It takes only a few seconds to attract customers' attention because their selection is intuitive and visual particularly in cosmetics market. Innovations in the packaging and development of new cosmetic packaging materials, as well as the way they are used, lead that intuitive selection to the right path. Good packaging not only defines the way in which the product is taken but also protects the product during transportation and use, so the product and the brand name will compete in the field. Since packaging is customer's first perception of a commercial title, it must have a long-lasting effect. Export statistics of the country, especially non-oil exports, indicate a low expansion of foreign trade and its reliance on elemental and traditional products. The country's significant export share is related to oil and gas and petroleum products, which, on average, accounts for $85 \%$ of the country's total exports. Moreover, in non-oil exports, it was almost related to traditional goods such as carpet, pistachio and saffron, and to some extent industrial products. Obviously, in such a situation, exports of industrial goods are not significant. This uneven ratio in the country's export mix reflects the country's economic reliance on exports of raw materials and non-industrial exports. In 2004, Iran ranked thirty-eighth in terms of the value of exports, accounting for only about $0.5 \%$ of the world's exports. Out of this amount of exports, only about $9 \%$ is related to manufactured goods. The losses of 2,600 billion Tomans due to the lack of proper packing, annually results in 2,600 billion Tomans of fruit losses (Zaribaf, 1382).

According to the information available in the case of packaging products such as apples, the transfer of this product to fruit and vegetable fields can be realized at a cost of 250 Tomans. However, now it is necessary to pay 130 Tomans for transportation of the same fruit without packing to the fields. In other words, only by paying a price of 120 Tomans per kilo while preventing products from deterioration and destruction, the goods will be loaded with better quality and minimum waste. The head of the fruit and vegetable union says: "We are in agreement with the proper packaging of agricultural products because this is in the interest of farmers and consumers."

\section{Methodology}

Deciding on the method of doing research depends on the purpose of the research, the nature of the problem and its various methods. So the research method should be selected according 
to the problem. The present study is descriptive. A sample population is a set of individuals or units that have at least one commonality. Usually, in each research, the community under study is a sample population that the researcher is willing to study the traits and variable of their units. In this research, sample population is the factories of the industrial town of Ardabil. The sampling method in this research is a multi-stage cluster. In the first stage, two regions have been selected with inappropriate packaging and export rate, and the other with appropriate packing and export rate. To investigate more in this research, the researcher has chosen 20 large factories randomly as the sample population.

In this research, a table is drawn up for analyzing each of the questions, which includes the frequency of responses, the percentage of frequency, total frequency and mean scores of responses. Scores of 1 to 5 have been given to obtain the average scores of responses to each of the none-to-high options of Likert scale. But for analyzing each of the research questions and hypotheses, a table similar to questionnaire table (questions) has been presented, in which the frequency of responses, percentage, total frequency, and an average of the scores are presented. For the hypotheses, the corresponding table similar to the questionnaire table is drawn with the difference that the questions related to each hypothesis are merged and their summation is written in a table. To analyze the obtained information, the frequency table of each question is first compiled. Using the percentage method, the percentage of frequency is calculated and the result of each question is given below the question. After analyzing each of the questions, we analyze the hypotheses of the research, which is accompanied by a graphic illustration of its results. Input analysis has also been used for inferential statistics.

\section{Results}

The following results are obtained from the analysis of the collected data.

Hypothesis 1: There is a meaningful relationship between the extent of good packaging and customer purchasing decision.

Table 1

\section{Impact or Rejection of the first Hypothesis}

\begin{tabular}{|c|c|c|c|c|c|c|c|}
\hline Total & Very low & low & To some extent & High & Very high & \multicolumn{2}{|c|}{ Options } \\
\hline 1050 & 29 & 81 & 364 & 425 & 151 & $\mathrm{f}$ & \\
\hline 100 & 2.76 & 7.71 & 34.66 & 40.47 & 14.38 & $\%$ & \\
\hline
\end{tabular}

According to table 1, we conclude that $14.38 \%$ of the sample population chose very high, $40.47 \%$ high $34.66 \%$ to some extent, $7.71 \%$ low and $2.76 \%$ chose very low options. Therefore, since the obtained average (3.56) is higher than expected, it can be concluded that there is a significant relationship between the amount of good packaging and customer purchasing decision. 


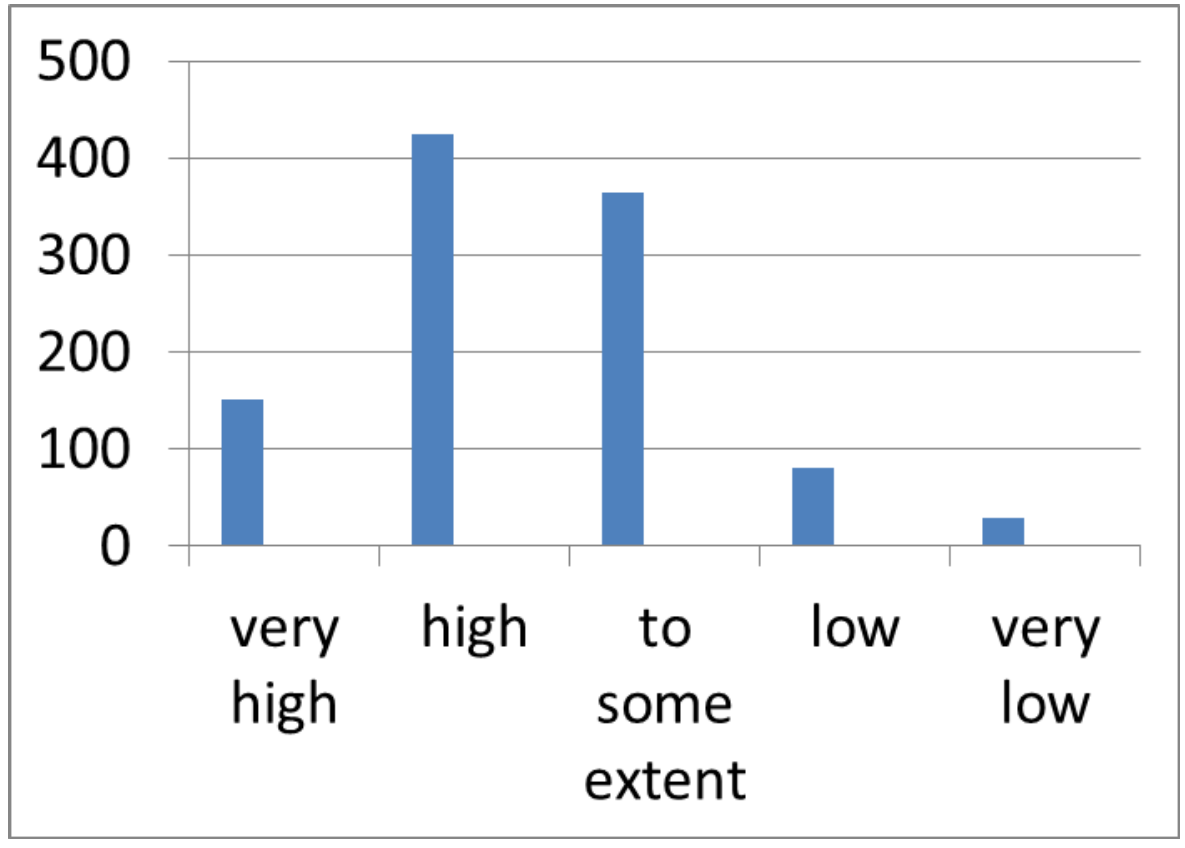

Figure 1. The relationship between the amount of good packaging and customer purchasing decisions

Hypothesis 2: There is a significant relationship between the size and shape of the good packaging and sales volume.

Table2

Confirmation or Rejection of the second Hypothesis

\begin{tabular}{|c|c|c|c|c|c|c|c|}
\hline Total & Very low & Low & To some extent & High & Very high & \multicolumn{2}{|r|}{ Options } \\
\hline 750 & 6 & 40 & 227 & 364 & 113 & F & Female \\
\hline 100 & 0.8 & 5.33 & 30.26 & 48.53 & 15.06 & $\%$ & \\
\hline
\end{tabular}

According to table 2, we conclude that 15.06 percent of the sample population chose very high, $48.53 \%$ high, 30.26 percent to some extent, 5.33 percent low and $0.8 \%$ chose very low options. Therefore, since the obtained average (3.71) is higher than the expected average, it can be concluded that there is a meaningful relationship between the size and shape of good packaging and the sales volume of the goods. 


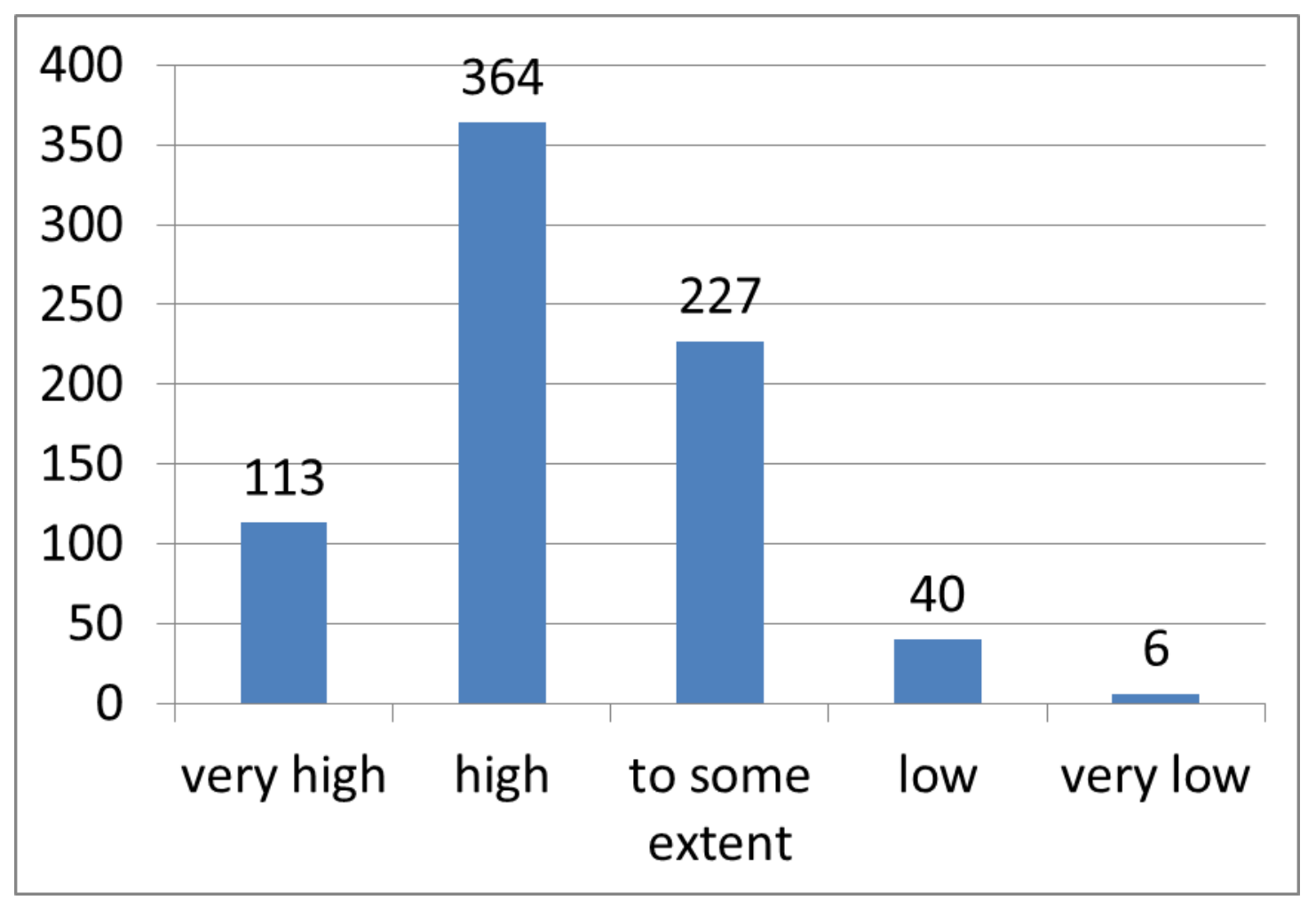

Figure 2. The relationship between the size and shape of good packaging and the sales volume

Hypothesis 3: There is a meaningful relationship between the factors such as color and design of packaging and sales.

Table 3

Confirmation or Rejection of third Hypothesis

\begin{tabular}{|c|c|c|c|c|c|c|c|}
\hline Total & Very low & Low & To some extent & High & Very high & \multicolumn{2}{|c|}{ Options } \\
\hline 300 & 3 & 6 & 83 & 143 & 65 & $\mathrm{f}$ & Female \\
\hline 100 & 1 & 2 & 27.66 & 47.66 & 21.66 & $\%$ & \\
\hline
\end{tabular}

According to table 3 , we conclude that $21.66 \%$ of sample population chose very high, $47.66 \%$ high, $27.66 \%$ to some extent, $2 \%$ low and $1 \%$ chose very low options. Since the average observation (3.87) is higher than the expected average, it can be concluded that there is a meaningful relationship between the factors such as color and design of packaging and sales of products. 


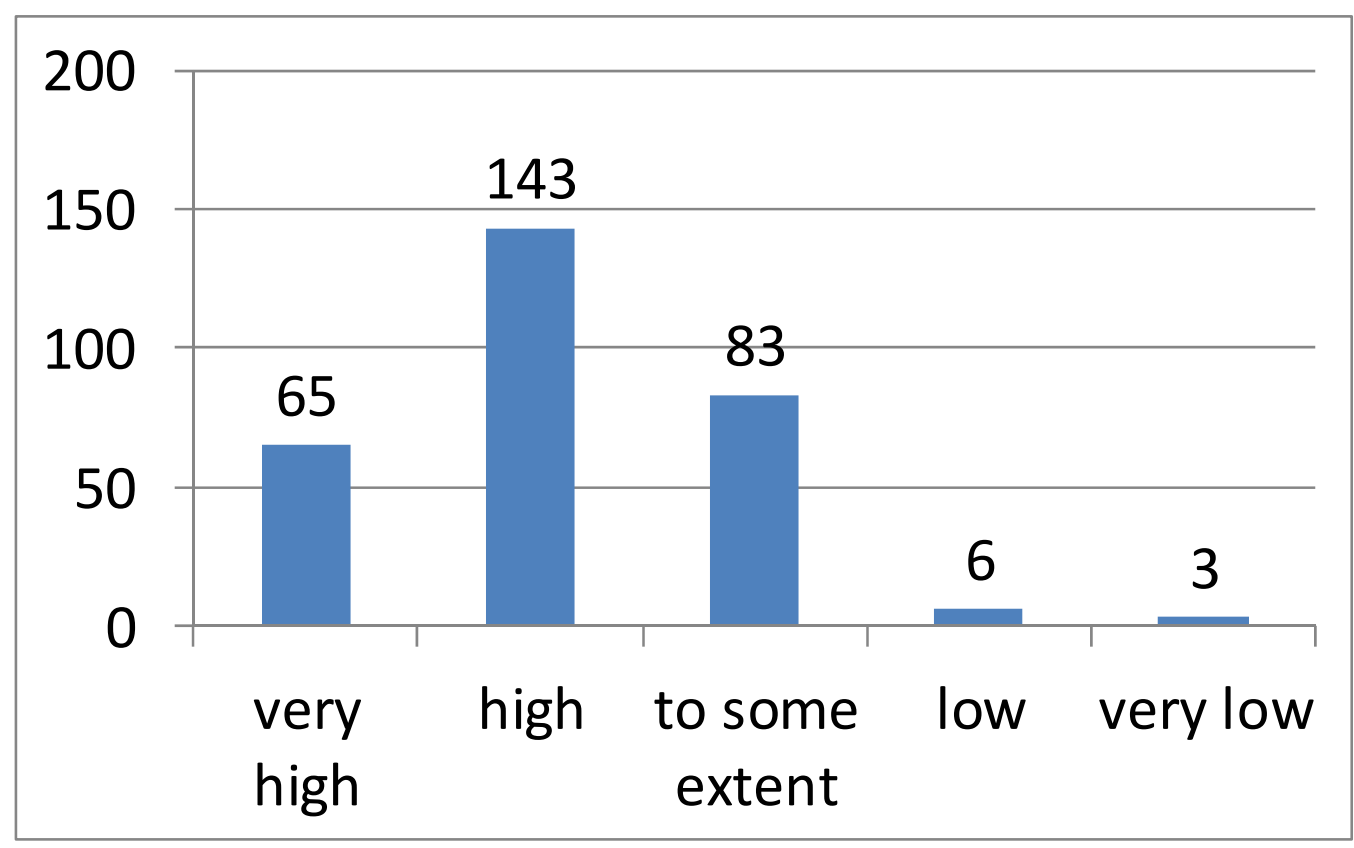

Figure 3. The relationship between factors such as color and design of packaging and product sales.

\section{Conclusion}

The results of the investigation of the first hypothesis indicating there is a meaningful relationship between appropriate packaging and customer purchasing decisions, showed that, 54.85 percent of the sample population chose very high and high options, 34.66 percent chose to some extent, and 10.47 percent chose low and very low options. Therefore, since the obtained average (3.56) was higher than the expected average, it can be concluded that there is a significant relationship between appropriate packaging and customer purchasing decision. So the first hypothesis was confirmed.

Investigation of the second hypothesis indicating that there is a significant relationship between the size and shape of appropriate packaging and the sales volume, showed that $63.59 \%$ of participants chose very high and high options, $30.26 \%$ chose to some extent, and $6.13 \%$ chose low and very low options. Since the obtained average was 3.71 higher than the expected average so, it can be concluded that there is a significant relationship between the size and shape of appropriate packaging and the sales volume, and this hypothesis was also and confirmed.

In examining the third hypothesis, the results showed that there is a significant relationship between the factors such as color and design of packaging and sales volume. The results also showed that 69.32 percent of participants chose very high and high options, 27.66 percent chose to some extent, and only 3 percent chose the low and very low options.

Moreover, the obtained average was 3.87 higher than the expected average. Therefore, it can be concluded that there is a significant relationship between the factors such as color and design of packaging and sales volume, and the third hypothesis was also confirmed.

The results of this research are in line with previous studies such as Semirom's research entitled "Food Industry and Agricultural Products, Investigating the Effect of Packing 
competitiveness and Hokmabadi's research entitled "The Study and Comparison of the Technical and Economic Properties of Two Types of Plastic Packaging in Two Packing Conditions".

The results of both studies emphasized the importance of packaging, which highly coincides with the results of this research. The results of product development, which means product design and selection of appropriate packaging solutions, have had a significant impact on the logical performance of the production chains. In spite of this, the old packaging process had an important role in the organization literature as it has influenced the development of literature. The purpose here is to show how performance of organizing and designing of products can be developed and enhanced through organizing of packaging in a company. Since there are lots of limitations with regard to possible solutions of logistics and organizing, packaging and organizing are often evaluated at the very last stages of the product development process. By evaluating the entire package, which includes product specifications, packaging and production chain, it is possible to make the necessary reserves at the first stages of development of the product. Packaging, designing and organizing of a product are closely interrelated. They can have a profound effect on the activities of the production chain together. It has been shown that product design might or might not provide the possibility of organizing, as it has a great impact on the organizing of the product during classification, collection, transportation, packaging, production, and so on.

Gaddy et al. (1940) argue that product designers should consider physical infrastructure for the development of their products as the design of a product affects organizing production chain. Hutch and Tedin Lee (1999) state that product design may include an assessment of the effects that affect decisions on design on the performance, maintenance, and transportation of a product. In the present study, it has been pointed out that the effect of packaging on product design is largely influenced by the organizing of packaging in a company, which also affects the logistics function and organizing a product. This section shows the strong relationship between product production, packaging and organizing activities. Packaging affects the product, and production and it also has a great impact on the final returns of the organizing process. The change in one of them has a significant effect on other cases, which is also evident in the possibility of lateral optimization (Kloves, 2015).

In this literature, packaging is often considered as part of the process of organizing and supplying, but a number of studies conducted on this issue indicate that if packaging function is related to the product development team and the function of organizing, so packaging coherence and product development is greatly assessed through the evaluation of the production chain and the preliminary data (Abeid, 2010).

Finally, it should be noted that in today's turbulent environments where companies operate, it makes sense that packaging is not a constant process, but should be considered as a dynamic process in designing different products. Therefore, on the basis of an appropriate index, it can be said that any change by the markets of sales can be based on new opportunities and threats in the field of organizing, marketing and technical areas. Moreover, managers understand that packaging can accurately distinguish consumer goods in a relatively similar way, and ultimately the survival of a number of brands in the market and the supply of various goods has led buyers to buy at the same time using the elements directly to distinguish 
different goods. The common results suggest that understanding the packaging technology plays an important role in the overall consumer willingness to buy specific products.

\section{References}

Abeid. R (2010). Quantification of Listeria monocytogenes in minimally processed leafy vegetables using a combined method based on enrichment and 16S rRNA real-time PCR. Journal of Food Microbiology, 27, 1923

Argents. P.A. \& Thea Haley, Fannie Mae, Goldman Sachs, 2013.

Ebied, M.C. Etc., "Going Global: Using IT to Advance Competitiveness of the Virtual Transnational Organization", P.13. 2010.

Faraji, M. (2001). Functional Purchasing Systems, Tehran: Imam Hussein University.

Garcia-Pascual, P., Mateos, M., Carbonell, V., and Salazar, D.M. 2003 Influence of storage conditions on the quality of shelled and roasted almonds. Biosystems engineering. 842: 201-209.

Kløve, B., 2015. Fully integrated surface-subsurface flow modelling of groundwater-lake interaction in an esker aquifer: Model verification with stable isotopes and airborne thermal imaging. Journal of Hydrology, 522, 391-406.

Kotler, P., \& Armstrong, G. (2010). Principles of marketing. Pearson education.

Ortega, D. L., Wang, H. H., Widmar, O., \& Nicole, J. (2015). Effects of media headlines on consumer preferences for food safety, quality and environmental attributes. Australian Journal of Agricultural and Resource Economics, 59(3), 433-445.

WIEBE, R.; GADDY, V. L. (1940): The solubility of Carbon Dioxide in water at various temperatures from 12 to $40^{\circ}$ and at pressures to 500 atmospheres. Critical phenomena. In J. Am. Chem. Soc. 62 (4), pp. 815-817. DOI: $10.1021 / \mathrm{ja} 01861 \mathrm{a} 033$.

Zaribaf, M. (2002). Managing World Markets, Tehran: Gostareshe Oloome Paye. 